\title{
Prophylactic postoperative ketorolac improves outcomes in diabetic patients assigned for cataract surgery
}

This article was published in the following Dove Press journal:

Clinical Ophthalmology

22 June 2013

Number of times this article has been viewed

\section{Moataz F Elsawy \\ Nermine Badawi \\ Hany A Khairy}

Ophthalmology Department, Menoufia University Hospital, Menoufia, Egypt
Correspondence: Moataz F Elsawy

Ophthalmology Department,

Menoufia University Hospital,

Menoufia, 532II, Egypt

Tel +20 100 24l 5133

Email mfelsawy@yahoo.co.uk
Objective: To evaluate the prophylactic role of topical non-steroidal anti-inflammatory drugs in reducing the incidence of central macular edema (CME) in diabetic eyes post-cataract surgery. Patients and methods: This study included 86 eyes ( 70 patients) with high risk characteristics for the development of CME after cataract surgery. All patients underwent phacoemulsification and intraocular lens implantation. Patients were divided into two equal groups ( $\mathrm{n}=43$ [eyes]): a control group given topical dexamethasone $0.1 \%$, four times/day for 12 weeks postoperatively and a study group given topical ketorolac tromethamine $0.4 \%$ twice daily in addition to topical dexamethasone $0.1 \%$ four times daily for 12 weeks. Patients were examined at 3, 6, and 12 weeks postoperatively for evaluation of CME development. The main study outcome was the change in the retinal fovea thickness measured with ocular coherence topography.

Results: Ten eyes developed CME (11.6\%); eight eyes in the control group and only two eyes in the study group. Mean retinal fovea thickness was significantly higher in the control group compared to the study group. Moreover, eyes of the control group developed CME significantly earlier than those of the study group.

Conclusion: Prophylactic postoperative ketorolac $0.4 \%$ may have a role in reducing the frequency and severity of CME in diabetic eyes post-cataract surgery.

Keywords: diabetes mellitus, cataract surgery, central macular edema, ketorolac, dexamethasone

\section{Introduction}

In recent times there has been a significant increase in the number of people with diabetes worldwide, and nearly 366 million people are estimated to be diabetic. By 2030, that number is expected to double, and this global increase will have a tremendous impact on the prevalence of diabetic complications. ${ }^{1}$

Diabetic eye disease is becoming an increasing problem due to longer life expectancy and a higher incidence of diabetes. Previous studies have mostly concentrated on diabetic retinopathy, but diabetes can affect virtually every part of the eye from the orbit, and lids, to the anterior and posterior segments, and occasionally it can significantly affect vision. Diabetes also influences lens transparency and pharmacological pupil dilatation. Cataract occurring in diabetic patients can be due to the diabetes itself or due to an accelerated senile cataract, in which case the cataract occurs earlier than normal. As with retinopathy, the duration and control of the diabetes are important factors in cataract development and management. ${ }^{2-5}$

Central macular edema (CME) is a painless condition in which swelling or thickening of the central retina (macula) occurs and is usually associated with blurred or 
distorted vision. The primary cause of CME depends on the underlying disease process, but most pathways eventually lead to vascular instability and breakdown of the blood-retinal barrier. The Müller cells in the retina become overwhelmed with fluid leading to their lysis, which results in an accumulation of fluid in the outer plexiform and inner nuclear layers of the retina. ${ }^{6,7}$

Ocular tissues, like those of other organs, exhibit welldefined morphologic reactions to local trauma and insult in the form of hyperemia, vasodilation, increased permeability of blood vessels, and edema. Cystoid macular edema remains a troublesome problem after cataract and other types of ocular surgical procedures. It is recognized as the most frequent cause of decreased vision in patients following cataract surgery. However, its cause is unclear, and all available therapeutic interventions, mainly based on theories regarding the pathogenesis of the condition, are of doubtful effectiveness and are still far from being satisfactory. Likewise, more insight into the phenomenon is being imparted by the agents being used in the preventative or curative line of management in CME. ${ }^{8,9}$

The magnitude of the problem of liability to develop post-cataract CME is more manifested and aggravated in diabetic eyes; this necessitates the search for preventive lines as opposed to therapeutic lines in order to safeguard against the development and/or amelioration of CME severity. ${ }^{10-12}$ Thus, the current study aimed to evaluate the prophylactic role of topical non-steroidal anti-inflammatory drug (NSAID), ketorolac tromethamine $0.4 \%$, against development of CME in diabetic eyes post-cataract surgery and its effect on the severity of affected eyes.

\section{Patients and methods}

The current prospective comparative study was conducted at El-Moada Eye Hospital (Shebin El-Kom, Menoufiya, Egypt) between Jan 2011 and March 2012. The study included 86 eyes (70 patients) with high risk characteristics for the postoperative development of CME.

Data collected from patients included age, past ocular and medical history, medications, allergies, and family history of glaucoma. Patients had baseline assessment at their preoperative visit, including best corrected visual acuity, intraocular pressure measurement with applanation tonometry, gonioscopy with three mirror Gonio contact lens, dilated fundus examination with $+78 \mathrm{D}$ volk lens, colour fundus photography, and central macular thickness with an ocular coherent tomography machine.

The study protocol was approved by the Ethical Committee of Menoufia Medical School. The study protocol was explained to the patients and all patients provided written informed consent.

Patients selected for the study had at least one of the risk factors for CME (beside diabetic retinopathy). Those risk factors included history of retinal vein occlusion, presence of epiretinal membrane, or preoperative use of prostaglandin analogues eye drops.

The randomization process used four opaque envelopes in two containers. The first container had (1) for dexamethasone drops only, and (2) for combined drops, and the second container had the name of patients listed for cataract surgery on that day. Patients were randomized to one of the regimes by asking an independent person to choose one envelope from each container.

All patients underwent phacoemulsification (divide and conquer technique) with foldable acrylic intraocular lens implantation by one experienced surgeon (MFE) using MEGATRON S3 (Geuder, Heidelberg, Germany). Throughout the follow-up period, patients were examined clinically for signs of CME and ocular coherent tomography was performed for measurement of central macular thickness at 3, 6 and 12 weeks postoperatively.

\section{Statistical analysis}

Obtained data are presented as means \pm standard deviation, ranges, numbers, and ratios. Results were analyzed using Wilcoxon ranked test for unrelated data (Z-test) and Chi-square test $\left(\chi^{2}\right.$ test). Statistical analysis was conducted using the Statistical Package for the Social Sciences (SPSS) version 15 (SPSS Inc., Chicago, IL, USA). A $P$-value $<0.05$ was considered statistically significant.

\section{Results}

The study included 86 eyes of 70 patients; 44 males and 26 females. Patients were divided equally between the two study groups. There was non-significant $(P>0.05)$ difference between both studied groups regarding the enrollment data (Table 1).

The mean retinal foveal thickness (RFT) in the study group was $258.08 \pm 16.8 \mu \mathrm{m}$ in the study group, and $256.92 \pm 17.1 \mu \mathrm{m}$ in the control group, with no statistically significant difference between the two groups $(P=0.0531)$.

All patients experienced a smooth intraoperative course with no significant intraoperative complications and were discharged uneventfully. Throughout postoperative follow-up, ten eyes developed CME, giving a total frequency of $11.6 \%$ irrespective of medication used. Eight eyes in control group and only two eyes in the study group developed CME, with 
Table I Patient enrollment data

\begin{tabular}{|c|c|c|c|}
\hline & Study group & Control group & Total \\
\hline \multicolumn{4}{|l|}{ Sex } \\
\hline Male & 23 & 21 & 44 \\
\hline Female & 12 & 14 & 26 \\
\hline \multicolumn{4}{|l|}{ Age in years } \\
\hline $50-60$ & 13 & 15 & 28 \\
\hline $6 I-70$ & 14 & 13 & 27 \\
\hline$>70$ & 6 & 9 & 15 \\
\hline \multicolumn{4}{|l|}{ Type of diabetes } \\
\hline Insulin dependent & 6 & 4 & 10 \\
\hline Non-insulin dependent & 27 & 33 & 60 \\
\hline \multicolumn{4}{|c|}{ Duration of diabetes in years } \\
\hline$<5$ & 9 & 9 & 18 \\
\hline $5-10$ & 22 & 21 & 43 \\
\hline$>10$ & 4 & 5 & 9 \\
\hline \multicolumn{4}{|c|}{ Risk factors for central macular edema } \\
\hline Retinal vein occlusion & 4 & 6 & 10 \\
\hline Epiretinal membrane & 2 & I & 3 \\
\hline Prostaglandin drops & 8 & 13 & 21 \\
\hline
\end{tabular}

significantly reduced frequency of CME in the study group $\left(\chi^{2}=3.696, P<0.05\right.$; Figure 1).

One eye in the study group developed angiographic $\mathrm{CME}$ at the 6th week with an RFT of $290 \mu \mathrm{m}$ and the other developed CME at the 12th week with an RFT of $275 \mu \mathrm{m}$. Conversely, in the control group, four eyes developed angiographic CME at the 3rd week with RFTs of 300, 320, 415, and $295 \mu \mathrm{m}$, respectively. Three eyes developed CME at the 6th week with RFTs of 310,320 , and $455 \mu \mathrm{m}$ respectively, and one eye developed CME at the 12th week with an RFT of $355 \mu \mathrm{m}$. Mean RFT on ocular coherent tomography was significantly higher in the control group compared to the study group $(P<0.05$; Figure 2$)$. Moreover, eyes in the

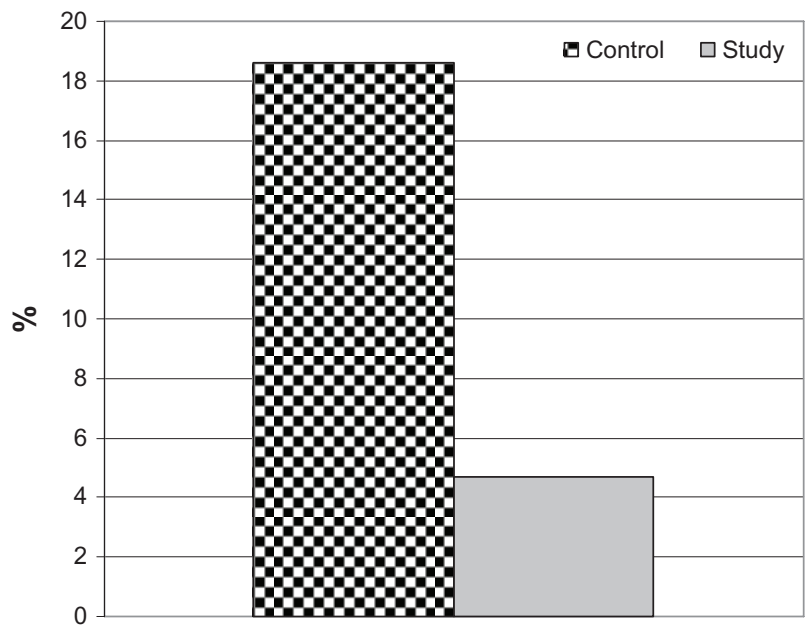

Figure I The frequency of development of central macular edema in both groups studied.

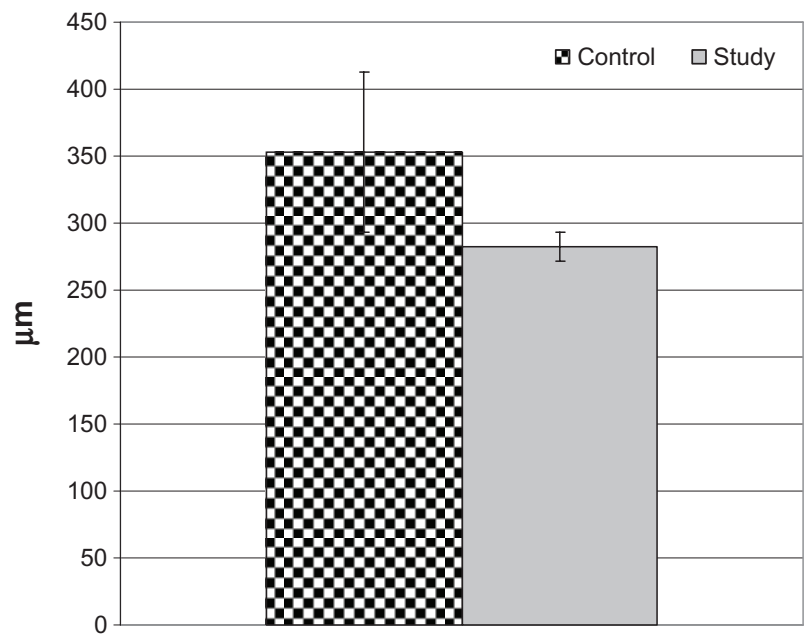

Figure 2 Mean retinal foveal thickness of eyes that developed central macular edema in both groups.

control group developed CME significantly earlier than those in the study group $(P<0.05$; Table 2 ; Figure 3$)$.

\section{Discussion}

The current study included 86 cataractous eyes in 70 diabetic patients assigned for phacoemulsification with intraocular lens implantation; all patients experienced a smooth intraoperative course and were discharged uneventfully. Throughout postoperative follow-up, ten eyes developed CME for a total frequency of $11.6 \%$, irrespective of medication used. Katsimpris et a ${ }^{13}$ compared central foveal thickness changes after cataract surgery between normal and diabetic patients without retinopathy and found that postoperative central foveal thickness in diabetics at all time-points of the followup period was significantly increased compared to controls,

Table 2 Mean postoperative RFT and time of onset of CME recorded in affected eyes

\begin{tabular}{|c|c|c|c|c|}
\hline & \multicolumn{2}{|l|}{ Control } & \multicolumn{2}{|l|}{ Study } \\
\hline & $\begin{array}{l}\text { RFT } \\
(\mu \mathrm{m})\end{array}$ & $\begin{array}{l}\text { Duration } \\
\text { (weeks) }\end{array}$ & $\begin{array}{l}\text { RFT } \\
(\mu \mathrm{m})\end{array}$ & $\begin{array}{l}\text { Duration } \\
\text { (weeks) }\end{array}$ \\
\hline \multirow[t]{8}{*}{ Differential } & 300 & 3 & 290 & 6 \\
\hline & 415 & 3 & 275 & 12 \\
\hline & 295 & 3 & & \\
\hline & 320 & 6 & & \\
\hline & 355 & 12 & & \\
\hline & 310 & 6 & & \\
\hline & 320 & 3 & & \\
\hline & 455 & 6 & & \\
\hline Total & $\begin{array}{l}352.9 \pm 60.1 \\
(295-455)\end{array}$ & $\begin{array}{l}5.6 \pm 3.2 \\
(3-12)\end{array}$ & $\begin{array}{l}282.5 \pm 10.6 * \\
(275-290)\end{array}$ & $\begin{array}{l}9 \pm 4.2^{*} \\
(6-12)\end{array}$ \\
\hline
\end{tabular}

Note: Data are presented as means \pm standard deviation; numbers ranges are in parenthesis; $* P<0.05$ versus control group.

Abbreviations: CME, central macular edema; RFT, retinal foveal thickness. 


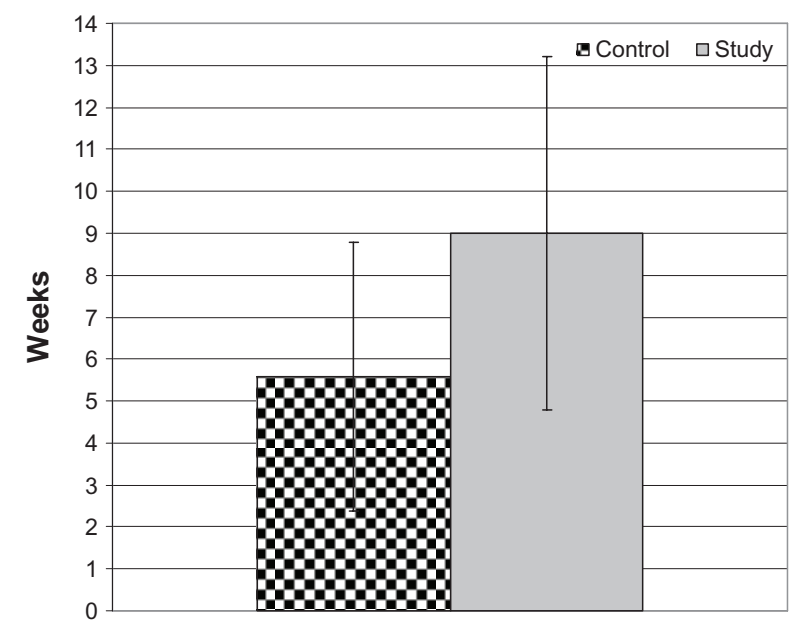

Figure 3 Mean postoperative duration until the development of central macular edema in both groups.

and the incidence of CME was $4.0 \%$ and $28.6 \%$ for controls and diabetics respectively. Also, Tsilimbaris et al ${ }^{14}$ reported a significant increase in mean foveal thickness in all patients at 1 and 3 months post-cataract surgery, but at 6 months the mean foveal thickness values returned to preoperative levels in the history-free and glaucoma patients, while it remained significantly higher in the diabetic and epiretinal membrane patients. Only two eyes in the study group developed CME, compared to eight eyes in the control group. This significant difference between the two groups demonstrates the beneficial effect of prophylactic therapy, irrespective of the medications used.

In support of prophylactic therapy, Singh et a ${ }^{15}$ evaluated nepafenac ophthalmic suspension $0.1 \%$ administered twice daily, beginning 1-day prior to cataract surgery and for 90 days postoperative for the prevention of macular edema in diabetic patients, and reported that a significantly lower percentage of patients in the nepafenac group developed CME relative to the vehicle group. Moreover, the mean central macular thickness and mean percent change from baseline in macular volume were also significantly lower in the nepafenac group versus the vehicle group.

Furthermore, Cervantes-Coste et a ${ }^{16}$ evaluated the impact of preoperative use of NSAIDs prior to cataract surgery and found prophylactic use of nepafenac was effective in reducing macular edema after cataract surgery and in maintaining trans-operative mydriasis. Also, Zanetti et a $\mathrm{l}^{17}$ found preoperative use of ketorolac, prednisolone, and nepafenac was effective in maintaining intraoperative mydriasis when compared to placebo.

Romac et $a l^{18}$ reported that combination of corticosteroid and NSAID is an effective and safe therapy for treating pseudophakic CME with significant improvement in visual acuity and retinal thickness at 2 months posttreatment. In support of the beneficial effect of the used combination therapy, mean retinal foveal thickness was significantly reduced and duration till development of CME was significantly shorter in patients who received combination therapy versus those who received topical steroid alone.

Miyake et $\mathrm{al}^{19}$ compared the use of topical NSAID (nepafenac $0.1 \%$ ) and a topical steroid (fluorometholone $0.1 \%$ ) in preventing CME after cataract extraction with a foldable intraocular lens implantation and found nepafenac was more effective than fluorometholone in preventing CME, and leads to more rapid visual recovery.

The choice of topical ketorolac as the NSAID is also a favorable choice as documented by Bucci and Waterbury ${ }^{20}$ who reported that ketorolac $0.45 \%$ achieved significantly greater aqueous concentrations when compared to bromfenac $0.09 \%$ and the active metabolite of nepafenac $0.1 \%$ (amfenac) in patients undergoing phacoemulsification. Moreover, Bucci and Waterbury ${ }^{21}$ compared prostaglandin E2 inhibition of ketorolac $0.45 \%$, bromfenac $0.09 \%$, and nepafenac $0.1 \%$ at peak dosing levels in patients scheduled to undergo phacoemulsification and found that ketorolac $0.45 \%$ achieved the greatest inhibition, and they concluded that ketorolac $0.45 \%$ may be more efficacious at controlling inflammation at the time of cataract surgery. Yilmaz et $\mathrm{al}^{22}$ in a systematic review found that treatment with ketorolac significantly reduced the risk of developing CME at the end of 4 weeks of treatment compared to controls.

\section{Conclusion}

To summarize, this study revealed that prophylactic postoperative ketorolac $0.4 \%$ may be an important factor in reducing the frequency and severity of CME in diabetic patients undergoing cataract surgery.

\section{Disclosure}

The authors report no conflicts of interest in this work.

\section{References}

1. Shaw JE, Sicree RA, Zimmet PZ. Global estimates of the prevalence of diabetes for 2010 and 2030. Diabetes Res Clin Pract. 2010;87(1): 4-14.

2. Ginter E, and Simko V. Global prevalence and future of diabetes mellitus. Adv Exp Med Biol. 2012;771:35-41.

3. Bron AJ, Brown NA, Harding JJ, Ganea E. The lens and cataract in diabetes. Int Ophthalmol Clin. 1998;38(2):37-67.

4. Shrestha RK. Ocular manifestations in diabetes, a hospital based prospective study. Nepal Med Coll J. 2011;13(4):254-256.

5. Adeoti C, Isawumi M, Ashaye A, Olomola B. The anterior segment of the eye in diabetes. Clin Ophthalmol. 2012;6:667-671. 
6. Guex-Crosier Y. The pathogenesis and clinical presentation of macular edema in inflammatory diseases. Doc Ophthalmol. 1999;97(3-4): 297-309.

7. Sakata K, Funatsu H, Harino S, Noma H, Hori S. Relationship of macular microcirculation and retinal thickness with visual acuity in diabetic macular edema. Ophthalmology. 2007;114(11):2061-2069.

8. Rossetti L, Autelitano A. Cystoid macular edema following cataract surgery. Curr Opin Ophthalmol. 2000;11(1):65-72.

9. Nagpal M, Nagpal K, Nagpal PN. Postcataract cystoid macular edema. Ophthalmol Clin North Am. 2001;14(4):651-659, ix.

10. Warren KA, Fox JE. Topical nepafenac as an alternate treatment for cystoid macular edema in steroid responsive patients. Retina. 2008;28(10):1427-1434

11. Johnson MW. Etiology and treatment of macular edema. Am J Ophthalmol. 2009;147(1):11-21. e1.

12. Zur D, Fischer N, Tufail A, Monés J, Loewenstein A. Postsurgical cystoid macular edema. Eur J Ophthalmol. 2011;21 Suppl 6:S62-S68.

13. Katsimpris JM, Petropoulos IK, Zoukas G, Patokos T, Brinkmann CK, Theoulakis PE. Central foveal thickness before and after cataract surgery in normal and in diabetic patients without retinopathy. Klin Monbl Augenheilkd. 2012;229(4):331-337.

14. Tsilimbaris M, Diakonis VF, Kymionis GD, et al. Prospective study of foveal thickness alterations after cataract surgery assessed by optical coherence tomography. Ophthalmologica. 2012;228(1):53-58.

15. Singh R, Alpern L, Jaffe GJ, et al. Evaluation of nepafenac in prevention of macular edema following cataract surgery in patients with diabetic retinopathy. Clin Ophthalmol. 2012;6:1259-1269.
16. Cervantes-Coste G, Sánchez-Castro YG, Orozco-Carroll M, Mendoza-Schuster E, Velasco-Barona C. Inhibition of surgically induced miosis and prevention of postoperative macular edema with nepafenac. Clin Ophthalmol. 2009;3:219-226.

17. Zanetti FR, Fulco EA, Chaves FR, da Costa Pinto AP, Arieta CE, Lira RP. Effect of preoperative use of topical prednisolone acetate, ketorolac tromethamine, nepafenac and placebo, on the maintenance of intraoperative mydriasis during cataract surgery: a randomized trial. Indian J Ophthalmol. 2012;60(4):277-281.

18. Romac I, Gabric N, Dekaris I, Barisic A. Resolution of pseudophakic cystoid macular edema with combination therapy of topical corticosteroids and nonsteroidal anti-inflammatory drugs. Coll Antropol. 2011;35 Suppl 2:281-284.

19. Miyake K, Ota I, Miyake G, Numaga J. Nepafenac $0.1 \%$ versus fluorometholone $0.1 \%$ for preventing cystoid macular edema after cataract surgery. J Cataract Refract Surg. 2011;37(9):1581-1588.

20. Bucci FA, Waterbury LD. A randomized comparison of to-aqueous penetration of ketorolac $0.45 \%$, bromfenac $0.09 \%$ and nepafenac $0.1 \%$ in cataract patients undergoing phacoemulsification. Curr Med Res Opin. 2011;27(12):2235-2239.

21. Bucci FA, Waterbury LD. Prostaglandin E2 inhibition of ketorolac $0.45 \%$, bromfenac $0.09 \%$, and nepafenac $0.1 \%$ in patients undergoing phacoemulsification. Adv Ther. 2011;28(12):1089-1095.

22. Yilmaz T, Cordero-Coma M, Gallagher MJ. Ketorolac therapy for the prevention of acute pseudophakic cystoid macular edema: a systematic review. Eye (Lond). 2012;26(2):252-258
Clinical Ophthalmology

\section{Publish your work in this journal}

Clinical Ophthalmology is an international, peer-reviewed journal covering all subspecialties within ophthalmology. Key topics include: Optometry; Visual science; Pharmacology and drug therapy in eye diseases; Basic Sciences; Primary and Secondary eye care; Patient Safety and Quality of Care Improvements. This journal is indexed on

Submit your manuscript here: http://www.dovepress.com/clinical-ophthalmology-journal

\section{Dovepress}

PubMed Central and CAS, and is the official journal of The Society of Clinical Ophthalmology (SCO). The manuscript management system is completely online and includes a very quick and fair peer-review system, which is all easy to use. Visit http://www.dovepress.com/ testimonials.php to read real quotes from published authors. 